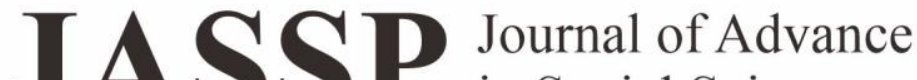 in Social Sciences and Policy
}

Editorial Office: Rectorate Building, Floor V, Jl. Prof. Dr. Sumantri Brojonegoro No. 1

Bandar Lampung, 35145, INDONESIA

Mobile: +62 813-6741-6145, Phone/Fax +62 721702767

Email: jassp@kpa.unila.ac.id, Website: https://jassp.lppm.unila.ac.id

Volume 1, Number 1, May 2021

\section{Political Parties And The Direction of Political Development in The Republic of Tatarstan}

\section{Политические Партии И Направление Политического Развития В Республике Татарстан}

\author{
Stanislav Vladimirov Mladenov ${ }^{1}$, Munadhil Abdul Muqsith ${ }^{2}$, Refly Setiawan $^{3}$ \\ ${ }^{1}$ Department of International Relations, Kazan Federal University, Russia \\ ${ }^{2}$ Department of Communication, Peoples' Friendship University (RUDN University), Russia \\ ${ }^{3}$ Department of Political Science, Kazan Federal University, Russia \\ Correspondence: Refly Setiawan, Kazan Federal University, Russia. E-mail: setiawan1992@mail.ru \\ Received: March 29, 2021 Accepted: May 11, 2021 Online Published: May 17, 2021
}

\begin{abstract}
:
Political parties reflect a democratic state, which is believed to be a condition for modern state life. As institutions for channeling interests, political parties are used as communication with a two-way function, namely, top-down and bottom-up. If this can be carried out well, then political parties' function as political socialization, political participation, political communication, articulation of interests, aggregation of interests, and policymaking can run well to realize the expected political development. The research method used in this research is qualitative research methods. Through qualitative research, the author has created a complex picture, examined words, reviewed detailed reports from the point of view of resource persons, and conducted studies on natural situations. This study aims to determine direction of political parties' development in the Russian Republic of Tatarstan, political parties' function, and political development amid a society in this modern era. The problem in this research is that political parties in Russia tend to have their own interests, either from the central government or the state or Federation governments. In addition, there tends to be a mismatch between the central and state governments in decision making. In fact, in the context political parties can be a tool for realizing development in a country. Even though there are problems, the results showed that political parties in the Republic of Tatarstan rated quite well in carrying out their functions by the functions of political parties according to the Law of the Russian Federation and the Law of the Republic of Tatarstan concerning Political Parties. The development of political parties in the Tatarstan Republic has played a role in controlling conflicts of interest among the Republic of Tatarstan.
\end{abstract}

Keywords: Political Parties, Direction of Development, Political Development, Republic of Tatarstan, Russia

\section{1. ВВЕДЕНИЕ}

Республика Татарстан - Республика Российская Федерация. Его территория входит в Приволжский федеральный округ и входит в Приволжский экономический район. Республика Татарстан образована Указом Центрального Исполнительного Комитета Всея России и Коллегии Народных Комиссаров 27 мая 1920 года как Автономная Татарская Социалистическая Советская Республика. Территория Республики Татарстан граничит с Кировской областью, Ульяновском, Самарой и Оренбургом, Республикой Башкортостан, Республикой Марий Эл, Удмуртской Республикой и Республикой Чуваш. Республика Татарстан расположена в центральной части европейской части России на ВосточноЕвропейской равнине, в месте слияния двух рек - Волги и Камы (Belyaev, 2007). Столица Республики Татарстан - город Казань, расположенный на востоке Москвы (Golosov, 2014). Большинство населения Республики Татарстан - мусульмане, а некоторые - православные христиане (Setiawan et al, 2020). Казань 
- третий по величине город после Москвы и Санкт-Петербурга. Население Казани составляет около 1,2 миллиона человек, и они говорят на двух языках, русском и татарском (Valeev, 2005).

Политическое развитие в Республике Татарстан продолжает набирать обороты. Важно понимать опыт политического развития и власти в Республике Татарстан, одним из которых является укрепление более высокого политического статуса и взаимосвязь между централизацией и децентрализацией власти. Сила региона в Республике Татарстан уникальна, потому что президент в этом регионе может быстро принять решение (Gabdrakhmanova, 2008). В Российской Федерации подсистема государственной власти может служить для распространения инноваций (Oversloot \& Verheul, 2006). Однако органы местного самоуправления также могут озвучивать интересы сообщества, сглаживать стремление к централизации и сохранять автономию (Sergey, 2020). Региональные власти могут обеспечить баланс политических интересов, учитывая требования общества при принятии политических решений. В этом случае правительство может обеспечить легитимность местных властей в отношении жителей и правительств других штатов (Djokic, 2020).

Парад суверенитета, проведенный летом 1990 г., увеличил институциональное разнообразие систем власти в республиках Советского Союза (Ilinskaya, 2018). Бывшие автономные республики и автономные области РСФСР повысили свой статус до статуса национально-государственной Федерации. Многие республики (Татарстан, Башкортостан, Тыва, Якутия, Чувашия) претендуют на власть и федеральные законы. В Чечне установился сепаратистский режим, угрожавший территориальной целостности и безопасности Российского государства и являвшийся этнократическим (Izmailov, 2018). В Республике Татарстан выбор уровня притязаний республиканских элит, методов и институциональных форм реализации их интересов зависит от объемов источников влияния и межэтнических отношений в каждом регионе. В сравнительном контексте Татарстан является одним из основных регионов ненасильственного суверенитета и индикатором политических партий в других республиках Российской Федерации. В этнополитической мобилизации элита Татарстана предпочитает правовой метод институционализации власти (Sergey, 2020). Референдум о статусе Республики Татарстан, состоявшийся 21 марта 1992 г. и получивший поддержку 61.4\% присутствующих избирателей, проект конфедерации получил легитимность (Ross, 2011). Развитие политических партий в Республике Татарстан показывает, что политика в республике продолжается и ощущается различными группами (Dolzhikova \& Moseykina, 2020). Проблема данного исследования заключается в том, что политические партии в России, как правило, имеют свои собственные интересы либо со стороны центрального правительства, либо со стороны правительства штата или Федерации. Кроме того, существует несоответствие между центральным правительством и правительством штата в принятии решений. Тогда как в данном контексте политические партии могут быть инструментом реализации развития в стране. Кроме того, политические партии, которые в настоящее время должны быть учреждениями по контролю за конфликтами, не управляются полностью оптимальным образом, поэтому требуется роль политических элит в управлении и осуществлении политического развития в обществе. Данное исследование направлено на определение того, как политические партии и политическое развитие в Республике Татарстан, Россия. Это связано с тем, что политические партии являются важным компонентом политической динамики страны. Политические партии рассматриваются как средство достижения власти отдельным лицом или группой лиц. Мы знакомы с подобными аргументами в различных средствах массовой информации и на различных семинарах, посвященных политическим партиям.

\section{2. МЕТОДЫ ИССЛЕДОВАНИЯ}

Метод использованный в данном исследовании, - это качественные методы исследования. По словам Сугийоно, качественная модель исследования уходит корнями в естественную среду, как целостность, полагается на людей как на инструмент исследования, использует качественные методы, проводит индуктивный анализ данных, направляет исследовательские цели на поиск теорий с земли, является описательной, ограничивает исследования, на которые нужно сфокусироваться, имеет набор критериев. Для проверки достоверности данных план исследования был предварительным, а результаты исследования согласовывались обеими сторонами, а именно исследователем и объектом исследования (Setiawan, 2017). Используя качественное исследование, автор создал сложную картину, изучил слова, подробные отчеты с точки зрения экспертов и провел исследования природных ситуаций (Farida \& Setiawan, 2018).

Аналитический метод, который использует автор, - это описательный качественный анализ, а именно метод анализа, который использует логическое мышление, логический анализ, индукцию, аналогию или интерпретацию, сравнение и тому подобное. Используемый метод мышления - это индуктивный метод, 
от данных или фактов до более высокого уровня абстракции, включая синтез и развитие теории (при необходимости и поддержке данных) (Muqsith, 2019). На основе этого анализа будут сделаны выводы в качестве ответа на существующие проблемы (Setiawan, 2016). Автор использует методику сбора данных посредством наблюдения, интервью и документирования. Исследование проводилось в Республике Татарстан, Россия, в течение 3 месяцев в 2020 году. Автор согласился с источниками исследования, а именно с депутатами законодательных органов от политических партий Республики Татарстан, о проведении интервью и использовании данных. этап триангуляции как инструмент измерения степени доверия. Источниками данных, используемых в этом исследовании, являются первичные и вторичные данные. Первичные данные получены из интервью с информантами, а вторичные данные получены из литературных источников, таких как книги и журналы, связанные с политическими партиями и политическим развитием в Республике Татарстан, Россия. В этом исследовании я использую метод триангуляции - это триангуляция по источникам, и есть надежда, что использование этого метода даст оптимальные результаты.

\section{3. РЕЗУЛЬТАТЫ ИССЛЕДОВАНИЯ И ОБСУЖДЕНИЕ}

\section{1 Политические партии в Республике Татарстан}

Этимологически политика происходит от слова «полис» (греческое), что означает город или городгосударство. Затем пошли слова polities, означающие граждан. В политическом плане он пытается достичь или реализовать идеалы или идеологию (Kuznetsov, 2020). Политические партии - это средство связи правительства и народа (Sintani et al, 2020). Первым, кто ввел слово «политика», был Аристотель в своих наблюдениях за «людьми, которые являются политическими животными» (Makarov, 2016). Он объяснил, что сущность социальной жизни - это на самом деле политика, и взаимодействие двух или более людей друг с другом обязательно будет включать политические отношения. В широком смысле каждый политик (Sergey, 2020). В этом отношении Аристотель утверждает, что единственный способ максимизировать способности человека и достичь высшей формы социальной жизни - это политическое взаимодействие с другими в рамках институциональной структуры, предназначенной для решения социальных конфликтов и формирования целей коллективного государства. Следовательно, каждый является политиком, хотя некоторые (государственные служащие) занимаются политической деятельностью больше, чем другие (Makarov, 2016). Государство и нацию можно интерпретировать как понимание, а именно, что высшая лояльность должна быть представлена национальному государству, в котором, во-первых, присутствуют элементы этнической принадлежности, языка и религии как общей идентичности (Erman \& Albintani, 2018).

В целом можно сказать, что политическая партия - это организованная группа, члены которой имеют одинаковую ориентацию, ценности и идеалы (Zubarevich, 2017). Эта группа стремится получить политическую власть и захватить политическое положение конституционным путем. Согласно Карлу Дж. Фридриху, политическая партия - это группа организованных людей, которые стабильно захватывают или сохраняют контроль над правительством для руководства своей партией и, на основе этого контроля, приносят своим членам идеальные и материальные выгоды (Sergey, 2020).

Политические партии в Республике Татарстан являются средством достижения власти политическими элитами. В настоящее время многие группы в Республике Татарстан заинтересованы во вступлении в политические партии. Многие хотят стать депутатами и надеются внести свой вклад в развитие Республики Татарстан. Несколько политических партий в настоящее время привлекают больше молодежи для объединения усилий и совместного развития (Gabdrakhmanova, 2008). Политические партии в Республике Татарстан имеют свою специализацию. Конституция Республики республики выводит Президента из системы разделения властей, не связывая его ни с одной из ветвей (Sergey, 2020). Согласно п. 89, Президент Республики Татарстан является «главой государства, высшим должностным лицом Республики Татарстан». Президент не входит в систему исполнительного органа (п. 3 ст. 9), но является главой исполнительной власти. В пункте 2 статьи 1 пункта 94 говорится, что президент «возглавляет систему исполнительного органа государственной власти в Республике Татарстан». Он определяет внутреннюю политику и направление внешней деятельности Татарстана (пункт 94 статьи 1 Конституции Республики Татарстан). Федеральный закон не регулирует работу премьер-министра. Он предусматривает, что высшее должностное лицо субъекта Федерации является главой высшего исполнительного органа субъекта Федерации. Но должности президента и главы правительства в Татарстане разделены (Valeev, 2005). Кроме того, политические партии также четко регулируются законодательством Республики Татарстан и постановлениями правительства.

Ниже приведены данные о признанных политических партиях в Российской Республике Татарстан: 
Таблица 1. Список политических партий Республики Татарстан в 2020 г.

\begin{tabular}{|c|c|c|}
\hline №. & Название Политической Партии & $\begin{array}{c}\text { Название Регионального Отделения Политической } \\
\text { Партии, Зарегистрированной В Республике Татарстан }\end{array}$ \\
\hline 1. & $\begin{array}{l}\text { Общероссийская политическая партия } \\
\text { «Единая Россия». }\end{array}$ & $\begin{array}{lcr}\text { Татарстанское } & \text { региональное } & \text { отделение } \\
\text { Общероссийской } & \text { политической } & \text { партии } \\
\text { Россия». } & & \text { «Единая } \\
& & \end{array}$ \\
\hline 2. & $\begin{array}{l}\text { Политическая } \\
\text { "Коммунистическая партия Российской } \\
\text { Федерации". }\end{array}$ & $\begin{array}{l}\text { Татарстанское региональное отделение политической } \\
\text { партии "Коммунистическая партия Российской } \\
\text { Федерации". }\end{array}$ \\
\hline 3. & $\begin{array}{l}\text { Политическая партия ЛДПР - } \\
\text { Либерально-демократическая партия } \\
\text { России }\end{array}$ & $\begin{array}{l}\text { Татарстанское региональное отделение Политической } \\
\text { партии - Либерально демократическая партия России }\end{array}$ \\
\hline 4. & $\begin{array}{l}\text { Политическая } \quad \text { партия } \\
\text { России" }\end{array}$ & $\begin{array}{l}\text { Региональное отделение Республики } \\
\text { политической партии «Патриоты России». }\end{array}$ \\
\hline 5. & $\begin{array}{l}\text { Общероссийская политическая партия } \\
\text { «Партия роста». }\end{array}$ & $\begin{array}{l}\text { Региональное представительство в Республике } \\
\text { Татарстан Общероссийской политической партии } \\
\text { «Партия роста». }\end{array}$ \\
\hline 6. & $\begin{array}{l}\text { Политическая партия "Справедливая } \\
\text { Россия" }\end{array}$ & $\begin{array}{l}\text { Региональное отделение Политической партии } \\
\text { «Справедливая Россия» в Республике Татарстан }\end{array}$ \\
\hline 7. & $\begin{array}{lr}\text { Политическая } & \text { партия } \\
\text { объединенная } & \text { "Российская } \\
\text { партия" (ЯБЛОКО) } & \end{array}$ & $\begin{array}{l}\text { Региональное отделение Политической } \\
\text { "Российская объединенная демократическая } \\
\text { ЯБЛОКтия" } \\
\text { ЯБ "в Республике Татарстан. }\end{array}$ \\
\hline 8. & $\begin{array}{lr}\text { Политическая } & \text { партия } \\
\text { "Республиканская } & \text { партия } \\
\text { Партия нарсии } & \text { Рной свободы". }\end{array}$ & $\begin{array}{l}\text { Региональный филиал не } \text { зарегистрирован } \\
\text { Республике Татарстан. }\end{array}$ \\
\hline 9. & $\begin{array}{l}\text { Политическая } \\
\text { "Демократическая партия России". }\end{array}$ & $\begin{array}{l}\text { Региональное представительство } \\
\text { Татарстан политической песпублике } \\
\text { партия России». }\end{array}$ \\
\hline 10. & $\begin{array}{l}\text { Политическая } \\
\text { "Коммунистическая } \\
\text { Коммунистов России" }\end{array}$ & $\begin{array}{l}\text { Республиканское отделение Политической партии } \\
\text { Коммунистическая партия Татарстана Коммунисты } \\
\text { России }\end{array}$ \\
\hline 11. & $\begin{array}{l}\text { Политическая партия "Российская } \\
\text { экологическая партия" Зеленые ". }\end{array}$ & $\begin{array}{l}\text { Региональное отделение Политической партии в } \\
\text { Республике Татарстан «Российская экологическая } \\
\text { партия« Зеленые ». }\end{array}$ \\
\hline 12. & $\begin{array}{l}\text { Общероссийская политическая партия } \\
\text { «Партия за справедливость». }\end{array}$ & $\begin{array}{l}\text { Региональное отделение } \\
\text { политической партии «Партия за справедливость» в } \\
\text { Республике Татарстан. }\end{array}$ \\
\hline 13. & $\begin{array}{l}\text { Политическая } \\
\text { будущего». }\end{array}$ & $\begin{array}{l}\text { Региональное отделение } \\
\text { политической партии «Партия свободных граждан»в в } \\
\text { Республике Татарстан. }\end{array}$ \\
\hline
\end{tabular}

\section{З.2 Политическое Развитие}

Обычно люди предполагают, что развитие - это нейтральное существительное, которое означает слово, используемое для описания процессов и усилий по улучшению экономической, политической, культурной, социальной инфраструктуры и т. Д. В этом понимании «развитие» приравнивается к слову «социальные изменения». " Для приверженцев этой точки зрения концепция развития самостоятельна. Для этого требуется другая информация, такая как развитие капиталистической модели, развитие модели социализма и т. Д. В этом смысле теория развития означает очень общую социальноэкономическую теорию. Эта точка зрения доминирует почти на всех уровнях общества (Farida \& Setiawan, 2018).

Между тем, с другой стороны, существует мнение большего числа меньшинств, которое отклоняется от предположения, что само слово «развитие» является дискурсом, идеологией и теорией социальных изменений. С этой точки зрения, сама концепция развития - это не нейтральное слово, а скорее поток, идеологические и теоретические убеждения и практики, касающиеся социальных изменений (Markov, 2016). При более глубоком рассмотрении с его базового понимания развитие используется в различных контекстах и часто используется в определенных политических и идеологических контекстах. Многие слова имеют то же значение, что и слово «развитие», например, социальные изменения, рост, прогресс и 
модернизация. С этих слов только социальные изменения означают изменение в более позитивном направлении. Следовательно, значение развития зависит от контекста, кто его использует и для каких целей. Планирование регионального развития является неотъемлемой частью национальной системы планирования развития (Setiawan \& Melinda, 2020).

В политическом развитии Республики Татарстан политическое образование всегда обозначалось как имеющее две сложные стороны. С одной стороны, совершенно необходимо осуществлять национальное образование на справедливой и устойчивой основе, по крайней мере, для того, чтобы все уровни общества (особенно в государствах) стали более политически осведомленными, осведомленными о законах и осведомлены об окружающей среде в самом широком смысле. Политическое образование играет жизненно важную роль в объединении нации (построении нации) (Sergey, 2020). C другой стороны, когда политическое образование породило несколько образованных обществ, в то время концепция целостного человека вышла на первый план, чтобы найти свое проявление в повседневной жизни. Политическое образование, которое изначально предназначалось для строительства нации, оказалось, что недостаточно основано на соображениях формальности академического образования, но оно также должно основываться на требованиях политических устремлений, вытекающих из академического образования (Kuznetsov, 2020).

Целью политического образования и преподавания в Республике Татарстан является формирование способных людей, понимающих политику и несущих ответственность за благосостояние общества. В соответствии с этими целями политического образования, цели политического образования в Республике Татарстан следующие (Sergey, 2020):

1. Показывать роль уникального человека или каждого человека как гражданина, максимально развивая потенциал и таланты;

2. Уметь активно участвовать в политическом процессе построения нации и государства.

Тем не менее, в контексте политического развития, это политическое образование в Республике Татарстан, особенно в подсекторе высшего образования, нравится вам это или нет, должно использоваться как стратегический инструмент для возрождения национальных лидеров, потому что с этого места Можно ожидать появления мыслителей прогресса нации и государства, особенно в эпоху коммуникации. Глобальный требует очень жесткой и междисциплинарной конкуренции. Сейчас не та эпоха, когда уместно ожидать, что лидеры государства опустятся на все социальные уровни и будут называть себя просто королями или королевами. Тем не менее, пора стимулировать открытость конкурентного мышления, чтобы продвигать нацию и государство в условиях глобальной цивилизации, которой больше нельзя манипулировать только формальной властью, которая носит временный характер (Zubarevich, 2017). Политическое развитие - это не просто политические изменения, но и устойчивое и справедливое развитие политической осведомленности людей. Это означает, что если политическое образование также должно выполнять миссию политического развития, то оно также должно продвигать всех людей, повышать осведомленность об их политических правах и обязанностях, улучшать их благосостояние и, конечно, также должно дополнять их желания как целые человеческие существа (Sergey, 2020).

\section{3 Политические Партии И Направления Политического Развития В Республике Татарстан}

Многие думают, что в каждой стране должна быть политическая партия. Многие также думают, что страны, в которых есть политические партии, являются развитыми странами. Даже в некоторой литературе объясняется, что политические партии являются частью демократического политического развития. Во многих странах нет политических партий, которые неизбежно должны строить демократическую политику. С другой стороны, в странах с политическими партиями, даже если они, кажется, применяют теорию демократического политического развития, они сталкиваются с реальностью, противоречащей демократическим ценностям (Sergey, 2020). Джеймс Роснау сказал, что функция политических партий состоит в объединении различных интересов в политической системе. В этом случае, по его словам, политические партии играют две важные роли в политической связке, а именно (Belyaev, 2007):

1. Как институт с проникающей функцией (проникающие связи) в том смысле, что это институт, который играет роль в процессе формирования государственной политики.

2. Как реактивная связь (взаимоотношения взаимодействия) - институт, который реагирует на политику государства. 
Васильевич Лазарев, как член партии «Единая Россия», сказал, что даже если политические партии в Республике Татарстан должны присутствовать в жизни людей, когда аристократические группы считаются уже несуществующими, это не означает, что преимущества политических партий не важный. Политические партии, которые сегодня известны широкой публике, являются институтами, контролирующими конфликты интересов в национальном политическом сообществе. Между тем, Дмитрий Нагиев, как член партии «Единая Россия», заявил, что политическая партия, действующая в настоящее время в Республике Татарстан, является институтом, который должен агрегировать, формулировать интересы, возникающие в обществе, включая социализацию политических ценностей, применимых к сообществу. обеспокоенный. Это функция политических партий, а именно (Sergey, 2020):

1) Политическая социализация: функция как процесс, посредством которого человек приобретает отношение и ориентацию по отношению к политическим явлениям, которые обычно применяются в обществе, в котором он находится;

2) Участие в политической жизни: функция, принадлежащая политическим партиям, призванная побудить общественность к активному участию в политической деятельности;

3) Политическая коммуникация: это функция передачи различных мнений и устремлений общества и их упорядочения таким образом, чтобы в обществе было меньше путаницы во мнениях.

4) Артикуляция интересов: функция выражения или передачи (артикуляции) интересов составляющих (общества) политическим и государственным органам через группы, которые они формируют вместе с другими людьми, разделяющими общие интересы;

5) Агрегация интересов: это функция политических партий, которая объединяет все устремления, существующие в обществе, которые затем формулируются как политическая программа и предлагаются законодательному органу, а кандидаты, предлагаемые на государственные должности, заключают сделки с группами интересов, с предлагать реализацию их интересов, если эта группа интересов желает поддержать кандидата;

6) Разработка политики: это функция, которую выполняет политическая партия после того, как политическая партия выиграла и сохранила власть в правительстве в соответствии с конституцией.

Холматович Саидов как член партии «Россия будущего» заявил, что если политические партии всегда оказываются в состоянии конфликта, это происходит потому, что их функция заключается в управлении конфликтами, даже если они часто создают новые конфликты. Политические партии - это «политические машины», необходимые для работы механизмов существующей политической системы. Политические партии - самая важная часть политической инженерии.

Выполняя свою функцию, группы будут определять политические партии и цели, которые необходимо достичь. Как заявил Матветов Исмаилиев как член партии «Единая Россия», он заявил, что революционная партия будет стремиться изменить весь порядок государственного устройства, культуру общества и экономическую систему в определенных условиях, и в случае успеха она будет контролировать каждую важную деятельность в этом обществе. В консервативной и традиционной партии происходит обратное, она лишь пытается сохранить свое положение.

Это соответствует целям, ожидаемым при создании и развитии политической партии, а именно (Sergey, 2020):

1. Стать средством самоактуализации граждан с высоким уровнем осведомленности для участия в политической жизни;

2. Стать форумом для агитации интересов;

3. Стать средством обретения и сохранения политической власти;

4. Стать местом сбора людей или групп, придерживающихся одинаковой идеологии и интересов.

Александр Переводчиков, заместитель председателя Исследовательского совета Ассамблеи ЛДПР, заявил, что политические партии в Республике Татарстан могут быть средством политического просвещения, которое может привести к политическим изменениям или развитию. Объектами изменений или политическими элементами, которые обычно наблюдают политологи, являются системы политических ценностей, структуры власти, стратегии решения проблем государственной политики и среда сообщества (социокультурные, экономические и технологические условия) и физическое (природные ресурсы) влияние. Они находятся под влиянием. политической системой.

Структура власти - это влияние инфраструктуры и надстройки в политическом процессе. Рассматриваемая инфраструктура - это политическая машина, существующая в обществе, которая напрямую не влияет на принятие государственных политических решений. Напротив, политическая 
надстройка - это политическая машина, которая напрямую влияет на принятие государственных политических решений (Sergey, 2020).

Инфраструктурная структура власти включает влияние различных социальных, религиозных и экономических групп в политическом процессе и влияние политических партий при объединении различных конфликтующих интересов в несколько альтернатив государственной политики. Надстройка власти включает в себя различные характеристики распределения и осуществления власти государственными учреждениями, такие как параметры власти (уровень использования силы и консенсус), распределение власти (степень централизации власти) и интенсивность власти (объем государственной власти и степени автономии инфраструктуры от государственного контроля) (Djokic, 2020).

В целом ученые упоминают два фактора, вызывающих политические изменения: конфликт интересов и новые идеи или ценности. Некоторые ученые указывают на конфликт интересов между различными группами (классами или ассоциациями) как на главную причину политических изменений. Согласно этой точке зрения, изменения являются результатом строго контролируемого взаимодействия интересов, даже определяемого социальным положением или материальными условиями вовлеченных элит. Для этого материалистического взгляда идеи или ценности отражают только интересы (Sergey, 2020).

Помимо конфликта интересов, изменения также могут происходить из-за появления новых идей или ценностей. Эта точка зрения рассматривает идеи и ценности как независимые переменные, объясняющие различия между социальными системами и процессами изменения и воспроизводства. Ценности создают в обществе не только динамизм и прогресс, но и магнетизм (Sergey, 2020). Общество будет развиваться и быть динамичным, если потребность в достижениях и успехе будет высоко оценена отдельными членами общества (Makarov, 2016). Еще один фактор, который также важен для осуществления изменений, - это различные преднамеренные, спланированные и организованные стратегии, разработанные и осуществляемые правительством.

\section{4. ЗАКЛЮЧЕНИЕ}

Можно сделать вывод, что политическую партию можно определить как форум для удовлетворения чаяний людей, реализации интересов общества и завоевания власти. Если политическая партия выполняет свои функции должным образом и в соответствии с идеологией и законами Республики Татарстан, можно гарантировать, что благосостояние общества будет достигнуто. Политическое развитие необходимо для развития нации. При наличии политического развития сообщество понимает функции и роли политических партий в обществе. Политические партии могут стать инструментом ускорения развития общества в Республике Татарстан и стать четким ориентиром для ускорения развития в нынешнюю эпоху модернизации и глобализации. Люди в Республике Татарстан также чувствуют себя причастными к политическому развитию своего региона благодаря хорошей синергии различных игроков, включая политическую элиту, правительство и население Республики Татарстан.

Ожидается, что политические партии обеспечат значимые изменения для страны, а именно позитивные изменения. При наличии политической партии демократическое государство, на которое надеялись, может быть реализовано до сих пор. Несмотря на то, что до сих пор на этой земле не было необходимости, которая обязывала бы каждую страну иметь политическую партию для устранения политических партий из нашего государства, жизнь кажется возвращающейся на несколько столетий назад. В настоящее время Россия начинает очищать и вносить изменения в различные аспекты, включая политические партии, и дает четкие направления развития политических партий в различных регионах, особенно в Республике Татарстан. Считается, что через правительство Республики Татарстан и существующие политические партии направление развития политических партий в Республике Татарстан выполнило цели этого региона, который стремится к миру и процветанию для всех слоев общества.

Хотя в России все еще существует проблема внутри политических партий, которые, как правило, имеют отдельные интересы как от центрального правительства, так и от правительства штата или Федерации при принятии решений. Однако политические партии в Республике Татарстан считаются достаточно хорошо выполняющими свои функции в соответствии с функциями политических партий в соответствии с Законом Российской Федерации и Законом Республики Татарстан о политических партиях. Другими словами, каким бы плохим ни был имидж политической партии в Республике Татарстан, он должен присутствовать как атрибут современности в образе нации и государства; 
Несмотря на то, что в некоторых странах нет политических партий, народ Республики Татарстан попрежнему придерживается демократических и политических ценностей. Правительство Республики Татарстан по-прежнему поддерживает целостность всех элементов общества и политических элит, которые все еще пытаются обеспечить хорошие изменения для прогресса и благосостояния общества. Синергия между Правительством, политическими партиями и обществом может быть реализована с чувством единства и достижения целей, которые были поставлены на основе идеалов татарского народа в России.

\section{БЛАГОДАРНОСТИ}

Исследование было поддержано Казанским федеральным университетом, всеми политическими партиями и Правительством Республики Татарстан. Автор хотел бы поблагодарить за поддержку различных сторон, вовлеченных в это исследование, особенно за предоставление данных, касающихся политических партий и направления политического развития в Республике Татарстан. Надеемся, что это исследование окажет большее влияние на политическое развитие Республики Татарстан, и результаты исследования могут быть полезны для всех слоев общества. Результаты этого исследования также могут быть использованы зарубежными исследователями не только из России, но также могут быть справочными для исследователей всего мира, связанных с политическими партиями и направлением политического развития.

\section{ИСТОЧНИК ЛИТЕРАТУРЫ}

Belyaev, V.A. (2007). Worldview and social behavior of the ruling elite of Tatarstan. Social Sciences and modernity: Kazan.

Djokic, A. (2020). The perspectives of Russia's soft power in the western Balkans region. Rude journal of political science, 22(2), 231-244. Https://doi.org/10.22363/2313-1438-2020-22-2-231-244

Dolzhikova, A. V., \& moseykina, m. N. (2020). Institutions and educational and cultural tools of migration policy in modern Russia. Rude journal of political science, 22(3), 387-400. Https://doi.org/10.22363/2313-1438-2020-22-3-387-400

Erman., \& Albintani, M. (2018). Politik Identitas dan Negara Bangsa di Riau. Nakhoda: Jurnal Ilmu Pemerintahan, Vol. 17 (29), 1-13.

Farida, I., \& Setiawan, R. (2018). Leadership in cope with prostitute in social department of Bandar Lampung. Samurai international journal of social sciences and development, 2(1), 1. Https://doi.org/10.24967/saburaiijssd.v2i1.325

Gabdrakhmanova, G.F. (2008). We are they (attitude towards migrants in the republic of Tatarstan). Sotsiol: kazan.Golosov, G.V. (2014). The territorial genealogies of Russia's political parties and the transferability of political machines. Post-soviet affairs. Vol. 30 (6). 464-480. Https://doi.org/10.1080/1060586x.2014.882106.

Ilinskaya, S. G. (2018). The sea of Russian culture (Russian identity and the concept of tolerance). Rude journal of political science, 20(4), 496-505. Https://doi.org/10.22363/2313-1438-2018-20-4-496-505

Izmailov, I.l. (2018). History is a factor in national mobilization. Kazan press: Kazan.

Kuznetsov, I. I. (2020). Great patriotic war in school literature: features of political socialization of students. Rude journal of political science, 22(2), 245-261. Https://doi.org/10.22363/2313-1438-2020-22-2-245261

Muqsith, M. A. (2019). Effect of fake news for democracy. Journal of chemical information and modeling, 53(9), 1689-1699. Https://doi.org/https://doi.org/10.15408/jch.v7i3.12956

Oversloot, H., \& Verheul, R. (2006). Managing democracy: political parties and the state in Russia. Journal of communist studies and transition politics. Vol. 22 (3). 383-405. Https://doi.org/10.1080/13523270600855795.

Makarov, G.M. (2016). Nagasaki and the history of civilization. Moscow press: Moscow.

Markov, r. (2016). Situation of the kryashens (book of the ethnological monitoring and early Warning network). Moscow media: Moscow.

Ross, C. (2011). The rise and fall of political parties in Russia's regional assemblies. Europe-Asia studies. Vol. 63 (3). 429-448. Https://doi.org/10.1080/09668136.2011.557535.

Sergey, S. (2020). The republic of Tatarstan: reduced to a common denominator?. Russian Politics \& law. Vol 56 (36). 222-235. Doi:10.1080/10611940.2019.1784627

Setiawan, R. (2017). Partisipasi publik dalam program bantuan listrik pedesaan Masyarakat kabupaten mesuji. Jurnal kebijakan \& pelayanan publik (e-jkpp), Vol. 3 (3). 82-92.

Setiawan, R. (2016). Peranan etika aparatur sipil negara dalam pelayanan publik pada Dinas kependudukan dan catatan sipil (disdukcapil) kota bandar lampung. Jurnal kebijakan \& pelayanan publik (e-jkpp), Vol. 2 (2), 46-57. 
Setiawan, R., \& Melinda, E. (2020). Optimization of the Implementation of Village Government in Indonesia. RUDN Journal of Public Administration. Vol 7 (4).

Setiawan, R., Abdurahman, A., Pertiwi, P. G., \& Saputri, S. (2020). Reaksi perekonomian rusia ditengah pandemi covid-19. 'adalah, Vol. 4 (1).

Sintani, F. A., Tuanaya, W., \& Wance M. (2020). Kaderisasi Dan Penetapan Calon Legislatif Pada Partai Politik (Studi DPD Partai Nasional Demokrat Seram Bagian Barat 2019). Nakhoda: Jurnal Ilmu Pemerintahan, Vol. 19 (1). 75-90.

Valeev, R. (2005). Tatars at home. Kazan press: kazan.

Zubarevich, N. (2017). The burden of the regions, what has changed in ten years?. Journal Russian Politics \& law, 55 (2), 61-76. Doi.org/10.1080/10611940.2017.1393269 